\title{
К ВОПРОСУ ОБ ОБЕСПЕЧЕНИИ ДОРОЖНО-ТРАНСПОРТНОЙ БЕЗОПАСНОСТИ ДПС ГИБДД
}

\begin{abstract}
Аннотация. Предметом исследования является срера транспортной безопасности, в частности деятельность ДПС ГИБДД в области обеспечения дорожно-транспортной безопасности, а именно выполнение подразделениями ДПС ГИБДД основной задачи дорожно-патрульной службы - обеспечение соблюдения участниками дорожного движения правил дорожного движения, в целях сохранения жизни, здоровья и имущества, защиты законных прав и интересов граждан и юридических лии, а также интересов общества и государства, обеспечение безопасного и бесперебойного движения автотранспорта. В статье приведены статистические данные тяжести дорожно-транспортных происшествий, что является общепризнанными показателями уровня безопасности дорожного движения. Решение проблем обеспечения дорожно-транспортной безопасности во многом зависит от повышения эффрективности деятельности ДПС ГИБДД. Автором анализируются формы и методы несения дорожно-патрульной службы. Контроль со стороны ДПС ГИБДД за соблюдением правил дорожного движения является действенным способом регулирования поведения участников дорожного движения. Контроль дорожного движения не может абсолютизироваться только выявляемостью административных правонарушений, а должен быть направлен на обеспечение безопасности дорожного движения, на минимизацию принуждения и наказания. Приоритетом, здесь должна служить профилактика причин и условий совершения дорожно-транспортных происшествий. Методологической основой исследования при написании статьи послужили статистический, формально-логический методы, а также общенаучные методы: дедукция, индукция, анализ и синтез. Автором сделан вывод о том, что деятельность ДПС гИБДД должна быть направлена на предупреждение причин возникновения дорожно-транспортных происшествий, снижения тяжести их последствий, в целях сохранения жизни, здоровья и имущества участников дорожного движения, а транспортная безопасность - это неотъемлемая часть общественной безопасности страны. Ключевые слова: дорожно-патрульная служба, дорожно-транспортные происшествия, аварийность, транспортная безопасность, участники дорожного движения, обеспечение дорожно-транспортной безопасности, правила дорожного движения, основная задача ДПС, выявляемость, административные правонарушения.

Review. The subject of the research is road safety, particularly the activities of traffic officers of the State Road Safety Inspectorate in the sphere of road safety and rules of the road observance provision with a view to preservation of life, health and property, protection of rights and interests of citizens and legal entities, interests of society and state, provision of safe and regular traffic. The author adduces statistical data of serious traffic accidents serving as universally recognized indexes of road safety level. The solution of road safety problems depends on the enhancement of traffic officers' efficiency. The author analyzes the forms and methods of road safety service. Traffic police control over the rules of the road observance is an important way of traffic participants' behavior regulation. Traffic control cannot be absolutized only to administrative offences revelation; it should be aimed at road safety provision, minimization of coercion and punishment. Prevention of reasons and conditions of road accidents should be the top priority. The methodological base of the research includes the statistical and formal logical methods, and the general scientific methods of deduction, induction, analysis and synthesis. The author concludes that the work of traffic police should be aimed at the prevention of reasons of traffic accidents, reduction of severity of their consequences with a view to preservation of life, health and property of traffic participants, and road safety is an integral part of public security of the state.

Keywords: traffic officers' main task, rules of the road, road safety provision, traffic participants, road safety, accident rate, traffic accidents, traffic officers, revelation, administrative offences.
\end{abstract}

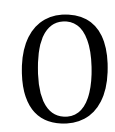
беспечение транспортной безопасности в Российской Федерации имеет актуальное значение. В настоящее время нельзя представить развитие экономики и социальной инфраструктуры без транспорта.
Как отмечается в постановлении Правительства Российской Федерации от 8 сентября 1997 г. № 1143 «Об одобрении концепции государственной транспортной политики Российской Федерации» транспорт - важнейшая составная часть произ- 
водственной инфраструктуры России. Его устойчивое и эффективное функционирование является необходимым условием стабилизации, подъема и структурной перестройки экономики, обеспечения целостности и национальной безопасности и обороноспособности страны, улучшения условий и уровня жизни населения.

Следует отметить, что в связи с произошедшими транспортными катастрофами за последнее десятилетие правовое регулирование этой области получило стремительное развитие, связанное с принятием Федерального закона от 9 февраля 2007 г. № 16-Ф3 «О транспортной безопасности», отраслевых приказов Минтранса России о требованиях по обеспечению транспортной безопасности, а также иных других правовых актов.

Таким образом, представляется возможным сделать вывод о том, что транспортная безопасность - это неотъемлемая часть общественной безопасности страны.

М. В. Костенников, исследуя правовое регулирование транспортной безопасности и роль полиции в ее обеспечении, пишет: «что для каждого вида общественной безопасности существует специальный административно-правовой режим ее обеспечения. В основу деления общественной безопасности на различные виды положен круг и характер общественных отношений, складывающихся в той или иной сфере жизнедеятельности. В административно-правовой литературе к сфере общественной безопасности обычно относят те общественные отношения, которые связаны с проявлением негативных свойств источников повышенной опасности при неправильном пользовании ими. В сферу общественной безопасности включают отношения людей, связанные с соблюдением правил, обеспечивающих безопасность дорожного движения; правил производства строительных и ремонтных работ в общественных местах; правил противопожарной безопасности; правил пользования предметами, подпадающими под лицензионно-разрешительную систему» ${ }^{1}$.

Государственная концепция обеспечения транспортной безопасности Российской Федерации ${ }^{2}$ - это система взглядов на обеспечение в Рос-

\footnotetext{
Костенников М. В. Правовое регулирование транспортной безопасности и роль полиции в ее обеспечении. Журнал «NB: Административное право и практика администрирования» / Содержание № 9 за 2013 год.

2 Государственная концепция обеспечения транспортной безопасности России разработана Минтрансом Рос-
}

сийской Федерации безопасности личности, общества и государства от внешних и внутренних угроз в транспортной сфере. В Концепции сформулированы важнейшие направления государственной политики Российской Федерации в этой сфере жизнедеятельности.

Государственная концепция обеспечения транспортной безопасности Российской Федерации включает в себя: определение национальных интересов в транспортной сфере, выявление факторов, создающих угрозу этим интересам, формирование системы противодействия негативным факторам и угрозам в этой сфере, определение комплекса мер, способных качественно повысить уровень транспортной безопасности Российской Федерации, привести его в соответствие с мировыми стандартами.

В настоящее время, среди множества проблем обеспечения транспортной безопасности, наибольшую озабоченность вызывает проблема обеспечения безопасности дорожного движения. Как составная часть транспортной безопасности, безопасность дорожного движения, как проблема касается не просто всех людей в целом, но и каждого в отдельности.

Обстановка на дорогах России, как и во всем мире, представляет реальную опасность демографии и национальной безопасности государства. Автомобильный транспорт в Российской Федерации является самым опасным видом транспорта. Из-за масштабов наносимого вреда, аварийность на дорогах отнесена $0_{00 H^{3}}$ к основным угрозам современности. В связи с этим, осуществление государственного контроля за соблюдением правил, стандартов, технических норм и других предписаний в области обеспечения дорожного движения в настоящее время признается одним из важнейших направлений деятельности органов государственной власти.

Данный вопрос нашел своё отражение и в постановлении Правительства Российской Федерации № 864 от 3 октября 2013 г. «0 федеральной целевой программе «Повышение безопасности дорожного движения в 2013 - 2020 годах», где целью

сии. Текст концепции в извлечениях опубликован в газете «Транспорт России» от 22 - 28 августа 2005 г. № 34 и полностью размещен на сайте газеты «Транспорт России». В Internet (http://www.transportrussia.ru).

3 Из послания Генерального секретаря ООН Пан Ги Муна по случаю начала Десятилетия на 64-й сессии генеральной ассамблеей $\mathrm{OOH}$. 
программы является сокращение случаев смерти в результате дорожно-транспортных происшествий, в том числе детей, к 2020 году на 8 тыс. человек (28,82 процента) по сравнению с 2012 годом (27991 погибших).

Поэтому, одним из важнейших направлений государственной политики в области безопасности дорожного движения являются: охрана жизни, здоровья и имущества граждан, защита их прав и законных интересов, а также защита интересов общества и государства путем предупреждения дорожно-транспортных происшествий, снижение тяжести их последствий.

Количество аварий, жертв и величина ущерба в автомобильном транспорте на 2-3 порядка превосходит показатели иных видов транспорта.

Из общего числа смертельно травмированных, $70 \%$ составляют лица в возрасте от 16 до 40 лет. Так, в период с января по ноябрь 2014 года в Российской Федерации произошло 181540 дорожнотранспортных происшествий, в которых погибли 24423 и получили ранения 228855 человек ${ }^{4}$.

Безусловно, для стабилизации обстановки с аварийностью, необходимо совершенствование дорожно-транспортной инфраструктуры, высокое правосознание населения и усиленная пропаганда соответствующих правовых норм. Тем не менее, ни одно государство не может обойтись без административно-правовых методов обеспечения безопасности дорожного движения, реализуемых преимущественно специализированными подразделениями дорожной полиции.

Несмотря на то, что полицейский контроль не может влиять на мотивы поведения участников дорожного движения, он признается обязательным и действенным средством предупреждения дорожно-транспортных происшествий, поскольку большинство из них прямо или косвенно связаны с грубыми нарушениями установленных правил. Основным субъектом полицейского контроля является дорожно-патрульная служба ГИБДД МВД России.

Дорожно-патрульная служба является крупнейшим подразделением Государственной инспекции безопасности дорожного движения МВД России (объединяет свыше 70 \% общей численности сотрудников ГИБДД), которой принадлежит важная роль в предупреждении дорожно-транспортных происшествий непосредственно в процессе дорожного движения, так как она является основ-

\footnotetext{
4 http://www.gibdd.ru. (Дата обращения 22.12.2014 г.).
}

ным субъектом в области системы обеспечения безопасности дорожного движения.

Правовую основу деятельности дорожно-патрульной службы составляют: Конституция Российской Федерации, Федеральный закон от 10 декабря 1995 г. № 196-ФЗ «0 безопасности дорожного движения», Федеральный закон от 30 декабря 2001 г. № 195-Ф3 «Кодекс Российской Федерации об административных правонарушениях», Федеральный закон от 7 февраля 2011 г. № 3-Ф3 «0 полиции», Указ Президента Российской Федерации от 15 июня 1998 г. № 711 «0 дополнительных мерах по обеспечению безопасности дорожного движения», постановление Правительства Российской Федерации от 23 октября 1993 г. № 1090 «0 правилах дорожного движения», иные нормативные правовые акты Российской Федерации, Наставление по организации деятельности дорожно-патрульной службы Государственной инспекции безопасности дорожного движения Министерства внутренних дел Российской Федерации, утвержденное приказом МВД России от 2 марта 2009 г. № 186 дсп «0 мерах по совершенствованию деятельности дорожнопатрульной службы Государственной инспекции безопасности дорожного движения Министерства внутренних дел Российской Федерации» и иные нормативные правовые акты МВД России.

Дорожно-патрульная служба осуществляет следующие функции: контроль на постах и маршрутах патрулирования дорожно-патрульной службы за соблюдением участниками дорожного движения правил дорожного движения; оказание содействия и помощи гражданам и юридическим лицам в осуществлении их законных прав и интересов при участии в дорожном движении; осуществление распорядительно-регулировочных действий; осуществление в соответствии с законодательством Российской Федерации производства по делам об административных правонарушениях; осуществление неотложных действий на месте дорожно-транспортных происшествий; осуществление мероприятий по сопровождению транспортных средств; разработка на основе анализа обстановки с аварийностью мер реагирования и предложений, направленных на сокращение числа дорожнотранспортных происшествий и пострадавших в них людей; информирование населения, в том числе с использованием средств массовой информации, о складывающейся обстановке с аварийностью, причинах дорожно-транспортных происшествий и принимаемых мерах по их предупреждению; проведение в порядке, определяемом нормативными 
правовыми актами МВД России, работы по розыску угнанных и похищенных автомототранспортных средств, а также автомототранспортных средств участников дорожного движения, скрывшихся с мест дорожно-транспортных происшествий; участие совместно с заинтересованными федеральными органами исполнительной власти, органами местного самоуправления, организациями, независимо от форм собственности, общественными объединениями, а также гражданами в реализации профилактических мероприятий, направленных на обеспечение безопасности дорожного движения; контроль за эксплуатационным состоянием и обустройством улично-дорожной сети и средств регулирования, соблюдением установленных условий производства ремонтно-строительных работ на автомобильных дорогах, улицах и площадях, принятие неотложных мер к устранению причин, создающих угрозу безопасности дорожного движения; обеспечение в пределах своей компетенции в соответствии с законодательными и иными нормативными правовыми актами Российской Федерации охраны общественного порядка и обеспечения общественной безопасности в зонах ответственности строевых подразделений; участие в пределах своей компетенции в выполнении задач, определенных планами перевода органов внутренних дел на военное время и действий при чрезвычайных (кризисных) ситуациях.

В наставлении по организации деятельности дорожно-патрульной службы ГИБДД МВД России, утвержденном приказом МВД России от 2 марта 2009 г. № 186 дсп, прописано, что основной задачей дорожно-патрульной службы является обеспечение соблюдения участниками дорожного движения правил дорожного движения в целях сохранения жизни, здоровья и имущества, защиты законных прав и интересов граждан и юридических лиц, а также интересов общества и государства, обеспечение безопасного и бесперебойного движения автотранспорта.

Для более полного анализа правовой природы данной функции представляется необходимым остановиться на краткой характеристике правил дорожного движения. В соответствии с пунктом 4 статьи 22, Федерального закона от 10 декабря 1995 г. № 196-Ф3 «0 безопасности дорожного движения», единый порядок дорожного движения на всей территории Российской Федерации устанавливается правилами дорожного движения, утверждаемыми Правительством Российской Федерации. Данные правила дорожного движения призваны регулировать общественное поведение участников дорожного движения и обеспечить безопасность везде, где возможно движение всех наземных транспортных средств, за исключением железнодорожных.

Контроль со стороны дорожно-патрульной службы ГИБДД за соблюдением данных правил является действенным способом регулирования поведения участников дорожного движения.

Контроль за соблюдением правил дорожного движения включает в себя:

1. Визуальное или с использованием технических средств наблюдение за движением транспортных средств и пешеходов;

2. Наблюдение за состоянием технических средств организации дорожного движения, проезжей части дорог и дорожных сооружений, элементами их обустройства ${ }^{5}$.

Контроль за дорожным движением может осуществляться:

1. В пешем порядке;

2. На патрульном автомобиле, мотоцикле или вертолетах;

3. На стационарном посту дорожно-патрульной службы.

Применение той или иной формы контроля определяется конкретными условиями дорожного движения и соответствующими служебными задачами нарядов дорожно-патрульной службы гиБдД 6 .

Абсолютизация выявляемости правонарушений уводит на второй план основную задачу дорожно-патрульной службы ГИБДД.

Заметим, что в последнее время наблюдается и увеличение тенденции к погоне за «собираемостью» штрафов за правонарушения, выявленных с помощью технических средств видеофиксации.

В силу того, что выявить, пресечь и документально оформить все нарушения правил дорожного движения практически невозможно, сотрудники дорожно-патрульной службы ГИБДД должны быть хорошо знакомы с результатами анализа аварийности в обслуживаемой зоне и на этой основе использовать основную часть служебного времени на пресечение тех нарушений, которые являются наиболее опасными для данного участка.

\footnotetext{
Административная деятельность органов внутренних дел. Часть Особенная: Учебник. - М.: ЦОКР МВД России, 2009. - C. 182.

6 Зейналов Ф.Н. Особенности форм и методов несения ДПС // Наука и практика. - 2010. - № 2. - С. 52-53.
} 
Если же сотрудники дорожно-патрульной службы сориентированы только на «выявляемость», то ничто не помешает им применять меры взыскания в отношении лиц, совершивших так называемые формальные правонарушения, не оказывающие серьезного влияния на безопасность дорожного движения, либо преимущественно такие, выявление и документальное оформление которых не представляет особых трудностей, ни в физическом, ни в психологическом плане.

Для подразделений дорожно-патрульной службы конечные результаты невозможно определить только качественными показателями. Собственно говоря, мы можем полагаться только на косвенные показатели, такие, как количество дорожно-транспортных происшествий, погибшие и раненые на обслуживаемой территории, а также состояние дорожно-транспортной дисциплины среди различных категорий участников дорожного движения. Но и эти показатели не имеют, да и не должны иметь определенных норм. И поэтому, в качестве косвенного критерия эффективности деятельности дорожно-патрульной службы, используется динамика аварийности, т.е. сравнение числа дорожно-транспортных происшествий по определенным участкам, периодам, времени, категориям транспортных средств и т.д.

Однако на практике чрезвычайно трудно установить взаимозависимость активности отдельных инспекторов дорожно-патрульной службы в несении службы и показателей аварийности, вопервых, потому, что дорожно-транспортная аварийность - процесс многофакторный, во-вторых, из-за того, что в подавляющем большинстве случаев нет возможности обеспечить постоянное закрепление инспекторов за отдельными постами, маршрутами патрулирования, участками автомобильных дорог и т.д.

Сегодня инспектор дорожно-патрульной службы при несении службы «знает», что его основная задача, это выявление и составление $\mathrm{N}$ - количество нарушений правил дорожного движения. В карточке поста (маршрута патрулирования) указаны места концентрации дорожно-транспортных происшествий, где инспектор должен был нести службу и пресекать, предупреждать и выявлять на- рушения правил дорожного движения, однако он, как правило, выявляет нарушения лишь там, где «клюёт» или где можно легко выявить нарушения правил дорожного движения.

Как же на самом деле наряд дорожно-патрульной службы несет службу? Приведу пример. Допустим, что экипаж, согласно карточки поста (маршрута патрулирования) дислоцируется на месте концентрации дорожно-транспортных происшествий (например, нерегулируемый пешеходный переход), при этом он помнит поставленную задачу на инструктаже. В данном случае, наряд будет находиться за нерегулируемым пешеходным переходом, инспектор будет позволять водителям нарушать правила дорожного движения и по факту нарушения оформлять административные правонарушения, о выполнении основной задачи дорожно-патрульной службы говорить в этом случае не приходится. То есть, экипаж выявляет уже свершившиеся факты нарушений правил дорожного движения.

Возникает вопрос: выполняет ли наряд дорожно-патрульной службы свою основную задачу (предотвращает дорожно-транспортные происшествия, в целях сохранения жизни, здоровья и имущества участников дорожного движения). Конечно же, нет.

Суть контроля дорожного движения, как правоохранительного функционирования в социальной системе массового обслуживания, какой является автомобильный транспорт, не может не сочетаться с соответствующими методами и стилем работы дорожно-патрульной службы. Это должны быть методы, сориентированные на обеспечение безопасности дорожного движения, а именно, на минимизацию принуждения и наказания, приоритет убеждения и профилактики правонарушений, оказание помощи участникам дорожного движения, инициативное выявление их нужд и неукоснительное соблюдение законности.

В завершении, следует отметить, что обеспечение безопасности дорожного движения, как составная часть обеспечения транспортной безопасности - деятельность, направленная в первую очередь на предупреждение причин возникновения дорожно-транспортных происшествий, снижение тяжести их последствий.

\section{Библиография:}

1. Костенников М. В. Правовое регулирование транспортной безопасности и роль полиции в ее обеспечении. Журнал «NB: Административное право и практика администрирования» / Содержание № 9 за 2013 год.

2. Костенников М. В., Куракин А. В. Актуальные проблемы административного права. - М., 2013. 
3. Государственная концепция обеспечения транспортной безопасности России разработана Минтрансом России. Текст концепции в извлечениях опубликован в газете «Транспорт России» от 22-28 августа 2005 г. № 34 и полностью размещен на сайте газеты «Транспорт России». В Internet (http://www.transportrussia.ru).

4. Из послания Генерального секретаря ООН Пан Ги Муна по случаю начала Десятилетия на 64-й сессии генеральной ассамблеей $\mathrm{OOH}$.

5. Эектронный ресурс: http://www.gibdd.ru.

6. Комментарий к правилам дорожного движения Российской Федерации / Борбат А. В., Гирько С. И., Завидов Б. Д., Лебедев М.Ю.-М.: Проспект, 2006.-С. 7.

7. Барышников М. В. Административно-правовой статус участников дорожного движения.-М.: Юрлитиздат, 2008.C. 23.

8. Административная деятельность органов внутренних дел. Часть Особенная: Учебник.-М.: ЦОКР МВД России, 2009.-С. 182 .

9. Зейналов Ф. Н. Особенности форм и методов несения ДПС // Наука и практика.-2010.-№ 2.-С. 52-53.

10. Дмитриев С. Н., Под общ. ред.: Федоров В. А.: Дорожно-патрульная служба. Пособие для сотрудников ГиБдД 2-е изд., перераб. и доп. - М.: Спарк, 2000. - С.656.

11. Электронный ресурс: http://www.dni.ru/incidents/2011/10/13/220500.html.

12. Куракин А.В., Кулешов Г.Н. Государственная служба и информационные технологии // NB: Административное право и практика администрирования. - 2013. - 12. - C. 1 - 20. DOI: 10.7256/2306-9945.2013.12.10701. URL: http:// www.e-notabene.ru/al/article_10701.html

\section{References (transliterated):}

1. Kostennikov M. V. Pravovoe regulirovanie transportnoi bezopasnosti i rol' politsii v ee obespechenii. Zhurnal «NB: Administrativnoe pravo i praktika administrirovaniya» / Soderzhanie № 9 za 2013 god.

2. Kostennikov M. V., Kurakin A. V. Aktual'nye problemy administrativnogo prava. - M., 2013.

3. Gosudarstvennaya kontseptsiya obespecheniya transportnoi bezopasnosti Rossii razrabotana Mintransom Rossii. Tekst kontseptsii v izvlecheniyakh opublikovan v gazete «Transport Rossii» ot 22-28 avgusta 2005 g. № 34 i polnost'yu razmeshchen na saite gazety «Transport Rossii». V Internet (http://www.transportrussia.ru).

4. Iz poslaniya General'nogo sekretarya OON Pan Gi Muna po sluchayu nachala Desyatiletiya na 64-i sessii general'noi assambleei OON.

5. Elektronnyi resurs: http://www.gibdd.ru.

6. Kommentarii k pravilam dorozhnogo dvizheniya Rossiiskoi Federatsii / Borbat A. V., Gir'ko S. I., Zavidov B. D., Lebedev M.Yu.-M.: Prospekt, 2006.-S. 7.

7. Baryshnikov M. V. Administrativno-pravovoi status uchastnikov dorozhnogo dvizheniya.-M.: Yurlitizdat, $2008 .-S .23$.

8. Administrativnaya deyatel'nost' organov vnutrennikh del. Chast' Osobennaya: Uchebnik.-M.: TsOKR MVD Rossii, 2009.S. 182 .

9. Zeinalov F. N. Osobennosti form i metodov neseniya DPS // Nauka i praktika.-2010.-№ 2.-S. 52-53.

10. Dmitriev S. N., Pod obshch. red.: Fedorov V. A.: Dorozhno-patrul'naya sluzhba. Posobie dlya sotrudnikov GIBDD 2-e izd., pererab. i dop. - M.: Spark, 2000. - S.656.

11. Elektronnyi resurs: http://www.dni.ru/incidents/2011/10/13/220500.html.

12. Kurakin A.V., Kuleshov G.N. Gosudarstvennaya sluzhba i informatsionnye tekhnologii // NB: Administrativnoe pravo i praktika administrirovaniya. - 2013. - 12. - C. 1 - 20. DOI: 10.7256/2306-9945.2013.12.10701. URL: http://www.enotabene.ru/al/article_10701.html 